\title{
The smear layer created by scaling and root planing is physiologically eliminated in a biphasic process
}

Fernanda Regina Godoy ROCHA Daniela Leal ZANDIM-BARCELOS Carlos ROSSA JUNIOR José Eduardo Cezar SAMPAIO

Universidade Estadual Paulista - UNESP, School of Dentistry at Araraquara, Department of Diagnosis and Surgery, Araraquara, SP, Brazil.

Declaration of Interests: The authors certify that they have no commercial or associative interest that represents a conflict of interest in connection with the manuscript.

Corresponding Author:

José Eduardo Cezar Sampaio

E-mail: jsampaio@foar.unesp.br

DOI: 10.1590/1807-3107BOR-2015.vol29.0029

Submitted: Jul 10, 2014

Accepted for publication: Oct 15, 2014

Last revision: Dec 12, 2014

\begin{abstract}
Mechanical instrumentation of the root surface causes the formation of a smear layer, which is a physical barrier that can affect periodontal regeneration. Although different procedures have been proposed to remove the smear layer, there is no information concerning how long the smear layer persists on root surfaces after instrumentation in vivo. This study assessed the presence of the smear layer on root surfaces over a 28-day period after subgingival instrumentation with hand instruments. Fifty human teeth that were referred for extraction because of advanced periodontal disease were scaled and root planed (SRP) by a single experienced operator. Ten teeth were randomly assigned to be extracted 7, 14, 21, and 28 days after SRP. Another 10 teeth were extracted immediately after instrumentation (Day 0 , control group). The subgingival area of the instrumented roots was evaluated with scanning electron microscopy. Representative photomicrographs were assessed by a blinded and calibrated examiner according to a scoring system. A rapid and significant ( $p<0.05, \mathrm{Z}$ test) initial reduction in the amount of smear layer was observed at 7 days, and a further significant $(p<0.05)$ decrease was observed 28 days after SRP. Interestingly, even 28 days after SRP, the smear layer was still present on root surfaces. This study showed that the physiological elimination of the smear layer occurred in a biphasic manner: a rapid initial reduction was observed 7 days after instrumentation, which was followed by a slow process leading to a significant decrease 28 days after instrumentation.
\end{abstract}

Keywords: Smear Layer; Dental Scaling; Periodontal Attachment Loss; Regeneration.

\section{Introduction}

Destructive periodontal diseases promote pathological changes on periodontal tissues, including the resorption of alveolar bone, degradation of connective tissue attachment, and apical migration of the junctional epithelium along the root surface. ${ }^{1}$ Conventional cause-related therapy effectively arrests these events. Although it has proven to be effective, this therapy does not restore the original histological architecture of the periodontium; this leads to repair, a condition in which scar tissue reconstitutes neither the architecture nor the original function of the periodontium..$^{1,2}$

Classical studies have demonstrated that this reparative process results in the formation of a long junctional epithelium on the root surface instead 
of new connective tissue attachment. ${ }^{3,4}$ In fact, the regeneration of periodontal tissues is considered a highly unpredictable result because of a number of factors that can interfere with the regeneration process. The nature of the root surfaces that are affected by periodontal disease has been identified as one factor that interferes negatively with periodontal regeneration. ${ }^{1,5}$ Alterations of the pathologically exposed root surfaces can inhibit the formation of new connective tissue, even in the presence of progenitor cells that are capable of forming periodontal tissues. ${ }^{6}$

Exposure to bacterial enzymes and metabolites may induce physical, structural, chemical, and immunological changes on the root surface, making it an unsuitable substrate for cell adhesion and the attachment of collagen fibers. ${ }^{7,8}$ These surface changes alter the biochemical composition and mineral density, resulting in the appearance of resorption sites, loss of collagenous and noncollagenous proteins from the dentin matrix, retention and invasion of bacteria, and the adsorption of endotoxins. ${ }^{8,9,10}$ Chemical conditioning of the root surface is the first approach that has been used for regenerative therapy of the periodontium. Other techniques, such as guided tissue regeneration; autogenous, homogenous, and heterogenous bone grafts; synthetic implants; and the application of growth factors and other biological agents have been developed and used independently or in various combinations. ${ }^{1,2}$ In addition to the overall lack of predictability of these regenerative approaches, there is consensus in this field that no technique can be successful if the root surface is still contaminated.

The mechanical instrumentation of the root surface that is performed during periodontal treatment is of paramount relevance as it is intended to remove bacterial deposits and dental calculus. However, the root instrumentation creates an amorphous layer of inorganic and organic debris called the smear layer, which may interfere with periodontal healing. Microscopic analyses have shown that the smear layer contains residual calculus, cementum, bacteria, and bacterial-derived products. ${ }^{11,12}$ For this reason, the smear layer can act as a physical barrier between periodontal tissues/blood clots and the root surface, and it inhibits or hinders the formation of new insertions and possibly harbors bacterial growth. ${ }^{12,13,14}$
Because the effective removal of the smear layer could increase the potential for periodontal regeneration, many studies have assessed different chemical conditioning procedures for thorough elimination of the smear layer and exposure of the collagenous matrix. $15,16,17,18$

However, the clinical effectiveness of scaling and root planing procedures ${ }^{19}$ indicates that the smear layer does not prevent periodontal healing. Notably, there is no information in the literature regarding the behavior of the smear layer that is created by mechanical instrumentation. It is not clear whether the smear layer is left undisturbed or is not on the root surface after scaling and root planing. In this study, we assessed the presence of the smear layer in human teeth over time after subgingival mechanical instrumentation.

\section{Methodology Sample selection}

The study sample was comprised of 50 periodontally involved teeth in 15 patients who were 38 to 68 years of age. Patients were recruited from the Clinic of Periodontics in the School of Dentistry at Araraquara, Universidade Estadual Paulista - UNESP, Brazil. The patients were in good health with no contraindications to periodontal treatment. The following exclusion criteria were used: a history of antibiotic therapy within the previous 6 months and anti-inflammatory drugs within the previous 3 months, pregnancy or the use of contraceptives or any other form of hormone, current smoker or former smoker for $<5$ years, and/or periodontal treatment within the previous 6 months. Teeth were selected based upon the following criteria: probing depth and clinical attachment loss of $5 \mathrm{~mm}$ or more, radiographic evidence of at least $50 \%$ interproximal bone loss, and scheduled to be extracted with caries free roots. All patients were informed about the aims and methods of this study, and they gave their written consent to participate. The study protocol was approved by the local Research Ethics Committee (CEP-FOAr \#45/09).

\section{Procedure and experimental periods}

Before the extraction procedures, the periodontally affected teeth were submitted to subgingival scaling 
and root planing with hand instruments under local anesthesia along with the other teeth of the patient according to the established periodontal treatment plan. A single experienced trained periodontist performed the instrumentation, and the patients were properly instructed on oral hygiene.

After the instrumentation, a notch was placed on the root surface at the gingival margin with a high-speed cylindrical bur (KG Sorensen, Cotia, Brazil) to determine the subgingival area as well as to serve as a reference for the surface evaluation. The teeth were then extracted at weekly intervals up to 4 weeks after the instrumentation according to the experimental periods. After extraction, the teeth were carefully cleaned and immediately stored in $10 \%$ buffered formaldehyde for fixation. The clinical crowns were separated from the roots with a flexible diamond disc (KG Sorensen), and the root fragments were prepared for microscopic analyses. The samples were dehydrated in increasing grades of ethanol $(30 \%, 50 \%, 70 \%, 80 \%, 95 \% \text {, and } 100 \%)^{20}$ and dried overnight in a dehydration jar (Corning Life Sciences, São Paulo, Brazil). Finally, the samples were mounted on metallic stubs and sputter-coated with a $25-n m$ layer of $99.99 \%$ pure gold (Balt-Tec SCD-050, Balt-Tec, Kettleshulme, UK).

Based on the time lapse between subgingival instrumentation and extraction, the following experimental groups were formed $(n=10$ teeth per group): (i) Control - teeth extracted immediately after instrumentation; (ii) extraction performed 7 days after instrumentation; (iii) extraction performed 14 days after instrumentation; (iv) extraction performed 21 days after instrumentation; and (v) extraction performed 28 days after instrumentation.

After extraction, all of the patients included in the present study were appropriately referred to other clinics in the School of Dentistry at Araraquara according to their clinical restorative needs.

\section{Scanning Electron Microscopy}

Scanning Electron Microscopy (SEM) observations and records were performed on a scanning electron microscope (Jeol T330 A; Jeol USA, Inc., Peabody, USA) at $20 \mathrm{kV}$. Two photomicrographs of the central area of each sample (1,000X magnification) were obtained by a laboratory technician who was not aware of the study objective or the experimental groups. Using a single-blind method, the SEM photomicrographs were analyzed three times in 15-day intervals by a previously trained and calibrated examiner (kappa score $=0.93$ ) who used a scoring system to assess the presence of the smear layer. The three readings were averaged for each sample. The following scoring system was modified from a previous study and used in this study: ${ }^{20}$

1. Root surface completely covered by apparent smear layer;

2. Root surface partially covered by apparent smear layer; or

3. Root surface without apparent smear layer.

\section{Statistical Analysis}

For the statistical analysis, the samples were regarded as independent because the study design included the extraction of teeth in different experimental periods $(0,7,14,21$, or 28 days) and was not a longitudinal evaluation of the same tooth or sample. The proportions of samples classified as each score were compared between the periods with the $\mathrm{Z}$ test for proportions 9 (Microsoft Excel for Mac, version 12.3.6, Microsoft Corporation, Redmond, USA) with the significance level set at $95 \%$.

\section{Results}

The characteristics of the study samples are shown in Table. A rapid and significant decrease in the proportion of samples that were completely covered by an apparent smear layer (score of 1 ) was observed 7 days after instrumentation. Interestingly, no samples were completely covered with the smear layer 14, 21, and 28 days after instrumentation. The proportion of samples that were partially covered by the smear layer (score of 2) was relatively stable up to 21 days after instrumentation. The proportion of samples without a smear layer (score of 3 ) was increased significantly $(p<0.05)$ only 28 days after instrumentation (Figure 1). The average score for each experimental group is shown in Figure 2. In the control group, the root surface was completely covered by a uniform layer of debris without any indication of dentin tubules (Figure 2A). The root surface was 
Table. Characteristics of the volunteers and teeth included in the study.

\begin{tabular}{ll}
\hline Characteristics & \\
\hline Gender $(\mathrm{n})$ & 7 \\
$\quad$ Male & 8 \\
$\quad$ Female & $52.5 \pm 8.1^{*}(38-68)$ \\
Age (years) & $3.3 \pm 1.2^{*}(2-7)$ \\
Number of teeth/patient $(\mathrm{n})$ & $6.1 \pm 1.1^{*}(5-8)$ \\
Probing pocket depth $(\mathrm{mm})$ & 17 \\
Type of teeth $(\mathrm{n})$ & 11 \\
Molar & 5 \\
Pre-molar & 17 \\
Canine & \\
Incisor &
\end{tabular}

*mean \pm standard deviation

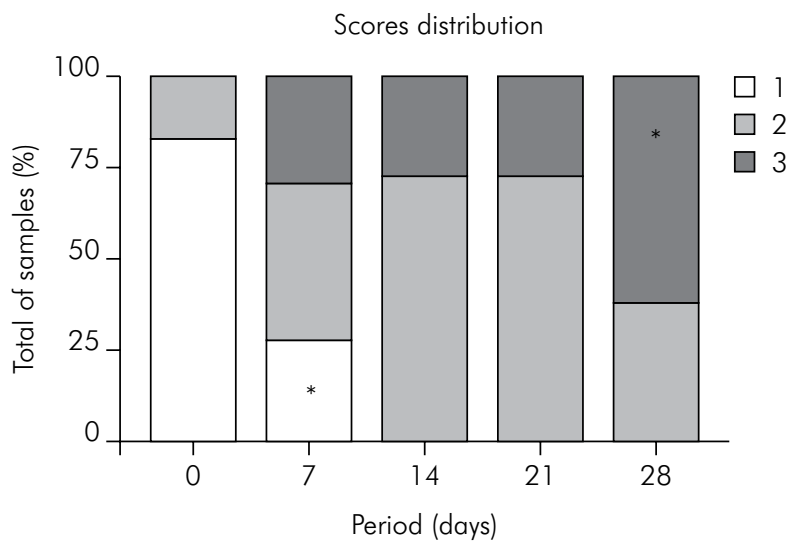

Figure 1. Relative distribution of the samples according to the scoring system in each experimental group $(0=$ control, 7 , 14,21 , and 28 days). *Significant difference compared to the control group ( $p<0.05, Z$ test comparing two proportions).

partially covered by a smear layer at 7 (Figure 2B), 14 (Figure 2C), and 21 (Figure 2D) days. The smear layer was completely absent and indications of dentin tubule openings could be observed at 28 days (Figure 2E).

\section{Discussion}

The results of the present study indicated the rapid initial conversion of surfaces that were completely covered by an apparent smear layer (score of 1) to surfaces that were partially covered by a smear layer (score of 2) during the first seven days after scaling and root planing. This change was interpreted as the initial step in the process underlying the gradual disappearance of the smear layer created after mechanical instrumentation. ${ }^{11}$ Interestingly, the smear layer was still present on the root surfaces 28 days after instrumentation. A rapid reduction in the smear layer was observed 7 days after instrumentation, and a further significant decrease was noted only after 28 days.

In the present study, the smear layer was created by scaling and root planing with hand instrumentation. Blomlöf et al..$^{21}$ have shown that different root planing modalities do not result in the same amounts of layer formation in human periodontitis-affected teeth. The diseased root surfaces were root planed by hand instrumentation, ultrasonic scaling, or round diamond burs. No differences in the root surface texture were observed after the three treatment modalities with respect to dentin exposure. The smear layer thickness varied from 3 to $10 \mu \mathrm{m}$, and there were no differences among the treatments. No open dentinal tubules were identified. ${ }^{21}$ Mishra and Prakash ${ }^{22}$ have evaluated the effects of hand instruments, ultrasonic scaling, and erbium-doped yttirum aluminum lasers on smear layer formation. Most of the specimens that were treated with hand instruments $(66.7 \%)$ and ultrasonic scaling $(80 \%)$ were covered by a smear layer, while the smear layer was not observed in most of the specimens treated with laser (60\%). A significant difference was found in the presence of the smear layer between ultrasonic scaling and laser treatments. ${ }^{22}$

It is important to determine how long the smear layer remains on the root surface after scaling and root planing as it may interfere with the biological events involved in the regeneration of periodontal tissues, ${ }^{1,12,23}$ particularly in the early phases of healing. The smear layer, which is interposed between the root and the tissues, can prevent blood clot adhesion and cell attachment to the root surface. ${ }^{24,25,26}$ For this reason, root conditioning has been used as an adjunct to mechanical root surface instrumentation in order to create a more biocompatible surface for early cell migration, attachment, cell-matrix interaction, fiber development, and, consequently, periodontal regeneration. Chemical agents, such as citric acid, tetracycline, and ethylenediaminetetraacetic acid, modify the root surface by removing the smear layer and endotoxins, opening dentinal tubules, and exposing the collagenous matrix..$^{1,11,12,18}$ A significantly higher amount of cell attachment occurs on demineralized 

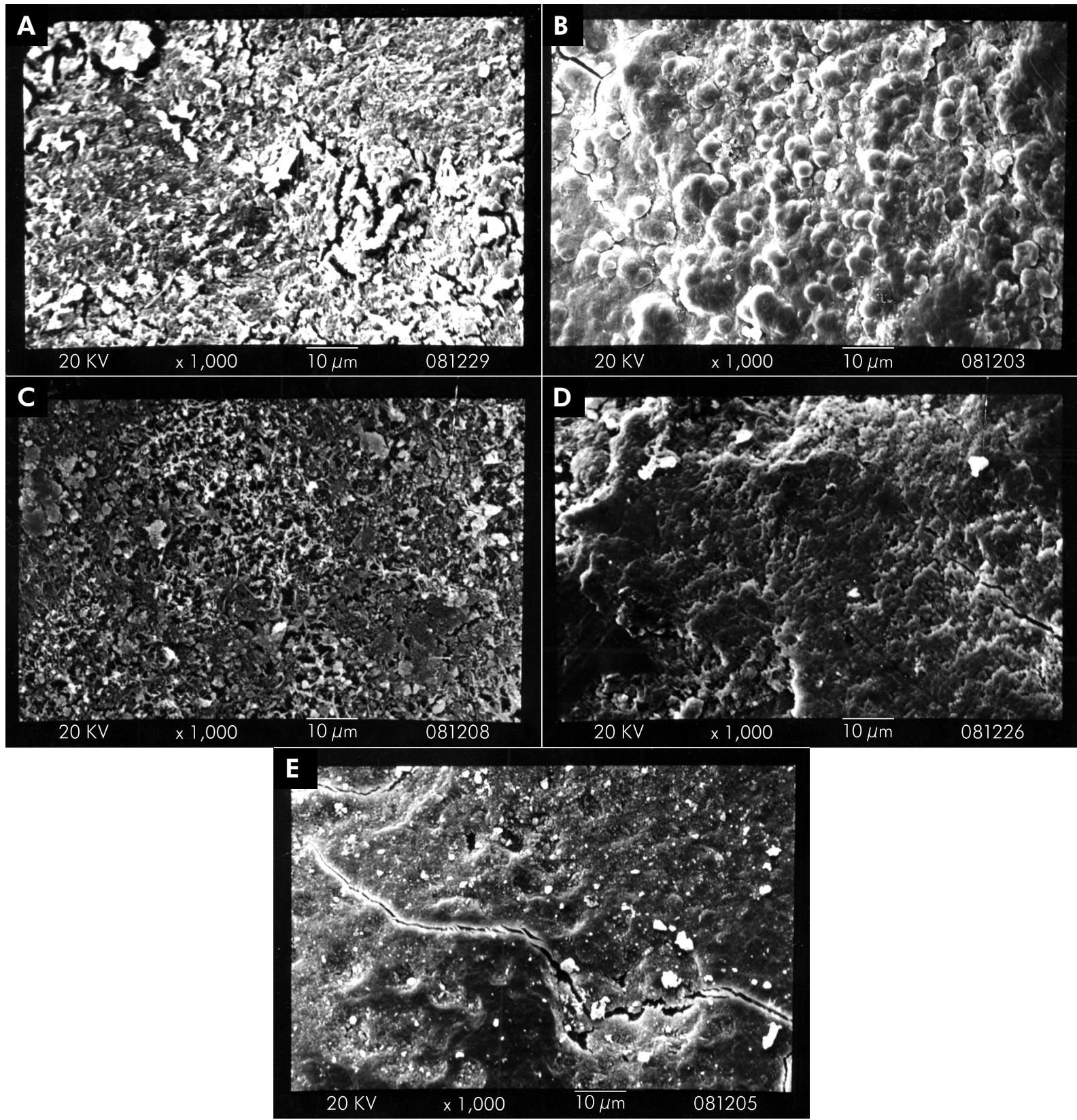

Figure 2. Representative scanning electron microscopy photomicrographs of the prevalent score for each experimental group. (A) At 0 (control), the root surface is completely covered by an amorphous smear layer; at (B) 7, (c) 14, and (D) 21 days, the root surface is partially covered by smear layer; $(\mathrm{E})$ at 28 days, the root surface is not covered by an apparent smear layer and areas of resorption are observed. (Bar $=10 \mu \mathrm{m}$; original magnification, $1,000 \mathrm{X}$ ).

dentin surfaces in vitro compared to nonetched dentin surfaces. ${ }^{25,26}$ The cellular responses to demineralized and nondemineralized dentin were studied in a subcutaneous transfixation model in rodents, and an improved response was reported in the demineralized samples, which present a surface that is similar to smear layer- free dentin compared to the nondemineralized dentin samples in which the surface is similar to smear layercovered dentin. ${ }^{23}$ In addition, fibrin linkage to exposed collagen fibrils on etched root surfaces prevents the apical migration of the epithelium and precedes collagen fiber attachment to the root surfaces. ${ }^{5}$ 
Several animal studies have shown favorable results of regenerative therapies that are associated with chemical root surface conditioning. ${ }^{7,27,28}$ However, the results of clinical studies in humans are controversial and reflect the poor predictability of regenerative therapies..$^{29}$ The inconsistent results of in vitro, in vivo, and clinical studies may be due to important root surface characteristics of periodontitis-affected teeth in humans, including differences in the degree of mineralization; exposure to various external agents, such as dental hygiene products, toothbrushing, toxins from tobacco products, nutrition-related acids, and biochemicals; caries experience; and aging. All of these factors are either not replicable or not considered in in vitro and in vivo preclinical studies of smear layer removal and the effects of root surface conditioning on regenerative procedures. The data on how long the smear layer that is created by mechanical instrumentation persists on the root surface is relevant for studies assessing periodontal healing, including repair and regeneration.

The mechanisms underlying smear layer elimination were not addressed in the present study, but it is tempting to speculate that this is an active process that is mediated primarily by inflammatory cells. In the early period subsequent to the instrumentation, a marked inflammatory process is associated with the disease process and the trauma from the instrumentation. This inflammatory process may be responsible for the rapid elimination of the smear layer that is observed as part of the biological process involving the migration of monocytic/macrophagic cells to the injury/inflammation site to remove the agents that are associated with the tissue damage. ${ }^{30}$

The finding that the elimination of the smear layer was a slow process may suggest that the formation

\section{References}

1. Lowenguth RA, Blieden TM. Periodontal regeneration: root surface demineralization. Periodontol 2000. 1993 Feb;1:54-68.

2. Wikesjö UM, Selvig KA. Periodontal wound healing and regeneration. Periodontol 2000. 1999 Feb;19(1):21-39.

3. Caton J, Nyman S, Zander H. Histometric evaluation of periodontal surgery. II. Connective tissue attachment levels of a long junctional epithelium is better than the formation of new connective tissue. New connective tissue attachment requires a clean dentin surface with exposed collagen fibers, which suggests why the repair is the most common healing response after mechanical instrumentation of teeth with periodontal disease.

Given the limited sample size, it is important to consider the factors that may influence the amount of smear layer that was created and its persistence on the examined teeth. The tooth type and the severity and nature of the periodontal disease may be related to the amount of local nonmineralized and mineralized deposits on the root surface, which requires more or less effort by the operator to attain a clinically smooth root surface. The age of the patient and the caries experience of the involved teeth, as well as diet- and oral hygiene-related issues (e.g., toothpaste, mouth rinses, and the consumption of low-pH beverages), are additional factors that may influence the conditions of radicular dentin and, consequently, the amount of smear layer formed. Even though all of these factors have to be considered when interpreting the results, the methodological approach used very closely resembled the routine clinical situation, which was a strength of this study.

\section{Conclusion}

This study showed for the first time that the physiological elimination of the smear layer that was created by mechanical instrumentation of the root surface occurred in a biphasic manner with a rapid initial reduction observed 7 days after instrumentation and a subsequent slow process resulting in a significant decrease of the smear layer 28 days after instrumentation.

after four regenerative procedures. J Clin Periodontol. 1980 Jun;7(3):224-31.

4. Caton J, Nyman S. Histometric evaluation of periodontal surgery. I. The modified Widman flap procedure. J Clin Periodontol. 1980 Jun;7(3):212-23.

5. Polson AM, Caton J. Factors influencing periodontal repair and regeneration. J Periodontol. 1982 Oct;53(10):617-25. 
6. Proye MP, Polson AM. Effect of root surface alterations on periodontal healing. I. Surgical denudation. J Clin Periodontol. 1982 Nov;9(6):428-40.

7. Polson AM, Proye MP. Fibrin linkage: a precursor for new attachment. J Periodontol. 1983 Mar;54(3):141-7.

8. Aleo JJ, De Renzis FA, Farber PA, Varboncoeur AP. The presence and biologic activity of cementum-bound endotoxin. J Periodontol. 1974 Sep;45(9):672-5.

9. Hatfield CG, Baumhammers A. Cytotoxic effects of periodontally involved surfaces of human teeth. Arch Oral Biol. 1971 Apr;16(4):465-8.

10. Adriaens PA, De Boever JA, Loesche WJ. Bacterial invasion in root cementum and radicular dentin of periodontally diseased teeth in humans. A reservoir of periodontopathic bacteria. J Periodontol. 1988 Apr;59(4):222-30.

11. Lasho DJ, O'Leary TJ, Kafrawy AH. A scanning electron microscope study of the effects of various agents on instrumented periodontally involved root surfaces. J Periodontol. 1983 Apr;54(4):210-20.

12. Polson AM, Frederick GT, Ladenheim S, Hanes PJ. The production of a root surface smear layer by instrumentation and its removal by citric acid. J Periodontol.1984 Aug;55(8):443-6.

13. Nalbandian J, Cote N. Direct histological comparison of periodontal wound healing in the beagle dog with and without citric acid conditioning. J Periodontol Res. 1982 Nov;17(6):552-62.

14. Hanes P, Polson A, Frederick T. Citric acid treatment of periodontitis-affected cementum. A scanning electron microscopic study. J Clin Periodontol. 1991 Aug;18(7):567-75.

15. Wirthlin MR, Hancock EB. Biologic preparation of diseased root surfaces. J Periodontol. 1980 May;51(5):291-7.

16. Daly CG. Anti-bacterial effect of citric acid treatment of periodontally diseased root surfaces in vitro. J Clin Periodontol. 1982 Sep;9(5):386-92.

17. Wikesjö UM, Nilvéus RE, Selvig KA. Significance of early healing events on periodontal repair: a review. J Periodontol. 1992 Mar;63(3):158-65.

18. Blomlöf L, Jonsson B, Blomlöf J, Lindskog S. A clinical study of root surface conditioning with an EDTA gel. II. Surgical periodontal treatment. Int J Periodontics Restorative Dent. 2000 Dec;20(6):566-73.

19. Heitz-Mayfield LJ, Trombelli L, Heitz F, Needleman I, Moles D. A systematic review of the effect of surgical debridement vs non-surgical debridement for the treatment of chronic periodontitis. J Clin Periodontol. 2002;29(Suppl 3):92-102.

20. Zandim DL, Corrêa FO, Rossa Júnior C, Sampaio JE. In vitro evaluation of the effect of natural orange juices on dentin morphology. Braz Oral Res. 2008 Apr-Jun;22(2):176-83.

21. Blomlöf JP, Blomlöf LB, Lindskog SF. Smear layer formed by different root planing modalities and its removal by an ethylenediaminetetraacetic acid gel preparation. Int J Periodontics Restorative Dent. 1997 Jun;17(3):242-9.

22. Mishra MK, Prakash S. A comparative scanning electron microscopy study between hand instrument, ultrasonic scaling and erbium doped:Yttirum aluminum garnet laser on root surface: A morphological and thermal analysis. Contemp Clin Dent. 2013 Apr;4(2):198-205.

23. Hanes PJ, Polson AM, Frederick GT. Initial wound healing attachments to demineralized dentin. J Periodontol. 1988 Mar;59(3):176-83.

24. Leite FR, Sampaio JE, Zandim DL, Dantas AA, Leite ER, Leite AA. Influence of root-surface conditioning with acid and chelating agents on clot stabilization. Quintessence Int. 2010 Apr;41(4):341-9.

25. Pitaru S, Melcher AH. Organization of an oriented fiber system in vitro by human gingival fibroblasts attached to dental tissue: relationship between cells and mineralized and demineralized tissue. J Periodontal Res. 1987 Jan;22(1):6-13.

26. Zaman KU, Sugaya T, Hongo O, Kato H. A study of attached and oriented human periodontal ligament cells to periodontally diseased cementum and dentin after demineralizing with neutral and low $\mathrm{pH}$ etching solution. J Periodontol. 2000 Jul;71(7):1094-9.

27. Polson AM, Proye MP. Effect of root surface alterations on periodontal healing. II. Citric acid treatment of the denuded root. J Clin Periodontol. 1982 Nov;9(6):441-54.

28. Register AA, Burdick FA. Accelerated reattachment with cementogenesis to dentin, demineralized in situ. I. Optimum range. J Periodontol. 1975 Nov;46(11):646-55.

29. Mariotti A. Efficacy of chemical root surface modifiers in the treatment of periodontal disease. A systematic review. Ann Periodontol. 2003 Dec;8(1):205-26.

30. Guyton AC, Hall JE. Textbook of Medical Physiology. 12th ed. St. Louis: Elsevier; 2011. Chapter 33, Resistance of the body to infection: I. Leukocytes, Granulocytes, the MonocyteMacrophage system, and Inflammation; p. 423-32. 